\title{
Hillslope geodiversity shapes ammonia-oxidizing communities and other microbial regulators in a semi-arid shrubland
}

\author{
Amir Szitenberg, ${ }^{\mathrm{a}, \mathrm{b},}$, Rivka Alexander-Shani ${ }^{\mathrm{a}}$, Hezi Yizhak ${ }^{\mathrm{c}}$, Ilan Stavi ${ }^{\mathrm{b}, \mathrm{d}}$ \\ ${ }^{a}$ Dead Sea and Arava Science Center, Dead Sea Branch, Masada 8693500, Israel \\ ${ }^{b}$ Ben-Gurion University of the Negev, Eilat 8858537, Israel \\ ${ }^{c}$ Department of Solar Energy and Environmental Physics, Blaustein Institutes for Desert Research, Ben-Gurion \\ University of the Negev, Sede Boqer Campus 84990, Israel \\ ${ }^{d}$ Dead Sea and Arava Science Center, Eilot Branch, Yotvata 8882000, Israel \\ *amir@adssc.org
}

HIGHLIGHTS

- Homogeneous hillslopes reduce soil water storage and increase aeration.

- Ammonia oxidizers and reducing-sugar degraders dwindle ammonia supply for plants.

- Homogenous hillslopes do not support moisture providing lichens.

- Reduced antibiotics and superoxide secretion capacitate pathogens.

- Geodiversity facilitates microbial regulation during drought.

\section{GRAPHICAL ABSTRACT}

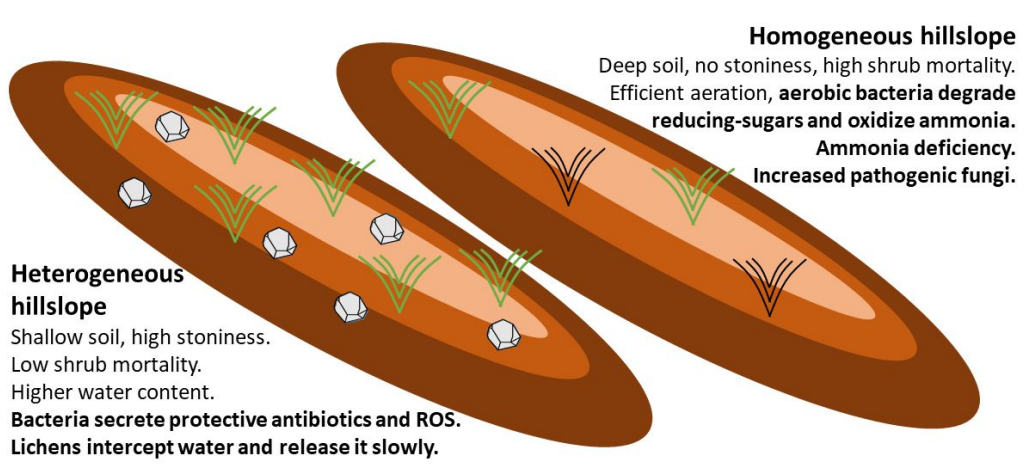

\section{ABSTRACT}

The determinants and consequences of drought-related shrub mortality were studied for over a decade, as a model for desertification processes, in a semi-arid long-term ecological research station. Recent studies have shown that geodiversity is an important spatial predictor of plant viability under extreme drought conditions. Homogeneous hillslopes, with a deep soil profile and lack of stoniness, could not support shrubs under long term drought conditions due to low water storage in their soil. Conversely, heterogeneous hillslopes, with shallow soil profiles and high stoniness, supported shrub communities under similar conditions, due to the comparatively greater soil-water content. In the current study, we investigated the effect of hillslope geodiversity on the soil microbial diversity. Using DNA metabarcoding, we found small but consistent differences in the microbial community compositions of the homogeneous and heterogeneous hillslopes; more ammonia oxidizing and reducing-sugar degrading bacteria are found in the homogeneous hillslopes, possibly dwindling the ammonia supply to shrubs. Additionally, based on functional metagenomic reconstruction, we suggest that homogeneous hillslopes have lower superoxide and antibiotics production, leading to reduced protection against pathogens. In fungi, we observed an increase in possible pathogens, at the expense of lichen forming fungi. Lichens are considered to support soil-water by slowly releasing intercepted raindrops. In conclusion, we show that not only plant-diversity but also microbial-diversity is shaped by geodiversity, and that the community shift in homogeneous hillslopes may further promote shrub mortality in this drought-prone, water limited ecosystem. 


\section{Introduction}

Climate change is predicted to alter precipitation regimes toward more frequent and severe drought events (Shukla et al., 2019). Consequently, understanding the direct effects of long term shifts in rainfall quantities and frequencies on biodiversity has been a major focus of ecological research (Beier et al., 2012; Hoover et al., 2014; Kreyling and Beier, 2013) and a key challenge for land managers (Briske et al., 2015; Smith, 2011). Such shifts may cause ecosystem transitions, which may lead to considerable and irreversible changes in biodiversity and ecosystem services (Díaz et al., 2019). Soil moisture changes directly affect plant productivity and survival, as well as mobilization of soil minerals and the diversity and activity of soil and plant microbiota (Dijkstra et al., 2015). The soil microbiome, in turn, plays vital roles in the cycling, mobilization and transport of nutrients, plant growth promotion, biocontrol of phytopathogens, water uptake capacity and abiotic stress response (Sze et al., 2020).

The spatial differences in lithological, topographic, and pedological properties of the soil, commonly regarded as geodiversity (Gray, 2005), are known to locally alter water storage in the soil profile and the mobilization of minerals (Okin et al., 2015; Stavi et al., 2018a). The interaction between this physical background and rainfall patterns, particularly in water-limited ecosystems, modulates the effects of climate change on biodiversity. Geodiversity effects on biodiversity have been studied mostly for plants and animals (Cartwright, 2019; Ibáñez and Feoli, 2013; Read et al., 2020; Stavi et al., 2018b; Stein et al., 2014), and for large geographic scales, such as watersheds and landscapes (Ibáñez et al., 2012; Janion-Scheepers et al., 2016). Millimetric scale pedodiversity as a driver of microbial diversity has also been investigated (Upton et al., 2019). Here, we aim to study the effects of geodiversity on the soil microbial diversity at the hillslope scale.

The Sayeret-Shaked Park in the Negev region of southern Israel is an established study site of regional desertification processes (Sher et al., 2012). Small-scale geodiversity in the region has been generated by the uneven spatial distribution of livestock traffic on the hillslopes (Stavi et al., 2018b, 2015). Concomitantly, hillslope-scale geodiversity was attributed to stoniness and depth of the soil profile (Stavi et al., 2019; Yizhaq et al., 2017). In both cases, elevated geodiversity was shown to alleviate the shortage of water for shrubs, increasing their durability under decreased precipitation regimes (Stavi et al., 2019; Yizhaq et al., 2017). Localized patches of high geodiversity were found to be critical for the survival of Noaea mucronata (Forssk.) Asch. \& Schweinf, the most common shrub species across the study area, under prolonged drought (Stavi et al., 2019). In this study we set out to understand the impact of geodiversity variation, generated by differences in stoniness and soil depth, on the bacterial and fungal communities in the soil and the consequent microbial functions. We hypothesized that the microbial community composition would differ between the hillslope types, because many microbes respond rapidly to changes in abiotic condition, with consequences to regulatory ecosystem services.

\section{Materials and methods}

\subsection{The study site}

The study was carried out in the Long Term Ecological Research (LTER) station of the Sayeret Shaked Park $\left(31^{\circ} 27^{\prime}\right.$ N, 34 $4^{\circ} 65^{\prime}$ E; 187 m.a.s.l.), in the semi-arid north-western Negev of southern Israel. The station, which covers an area of ca. 20 ha, has been fenced since the 1990s to prevent livestock grazing. The lithology 
is Eocene chalk and Plio-Pleistocene eolianites. The landform is dominated by rolling hills, with hillslope incline ranging between $3^{\circ}$ and $6^{\circ}$. The soil is classified as loessial Calcic Xerosol, with a sandy loam to loamy sand texture (Stavi et al., 2018a). Depth and stoniness of soil, as well as rock fragment cover percentage, are highly varied in the region (Singer, 2007). Multiannual mean daily temperatures are 26 and $12^{\circ} \mathrm{C}$ in the summer and winter, respectively, and mean cumulative annual precipitation has been $\sim 250 \mathrm{~mm}$ (Bitan and Rubin, 1991). However, during the first decade of the twenty-first century, precipitation rates sharply decreased (Shachak, 2011), averaging only $\sim 165 \mathrm{~mm}^{\bullet} \mathrm{y}^{-1}$. (Israel Meteorological Service website: http://www.ims.gov.il/ims/all tahazit/). The reduced precipitation was followed by a trend of mass shrub mortality, as observed by Sher et al. (2012), particularly among N. mucronata. For further regional and floral context see Stavi et al. (2018a).

\subsection{Sampling}

During February 2020, at the peak of the growth season, samples were collected from six 20 X 20 $\mathrm{m}$ plots, located on six adjacent hillslopes (Fig. 1A). Three hillslopes, previously characterized as homogeneous, have a soil profile deeper than $1 \mathrm{~m}$ and no stoniness, and three additional hillslopes, previously characterized as heterogeneous, have $\sim 0.1 \mathrm{~m}$ soil layer and high stoniness, accounting for $\sim 30 \%$ of the volume and $\sim 35 \%$ cover of the ground surface (Stavi et al., 2018a). The minimal distance between each pair of plots was $100 \mathrm{~m}$. To negate aspect-related and incline-related effects, all plots were delineated at a relatively similar azimuth $\left(310^{\circ} \pm 29^{\circ}\right)$ and slope $\left(5^{\circ} \pm 0.5^{\circ}\right)$. In each plot, we collected five soil samples from underneath the canopy of $N$. mucronata plants (shrubby patch) and five samples from an exposed area between shrubby patches (inter-shrub spaces), to reach a total of 60 soil samples. Each shrubby-patch sample was collected from an independent cluster of shrubs. To collect the samples, the soil was exposed with a trowel and a sterile $15 \mathrm{ml}$ tube was inserted to the exposed soil at 8-10 cm depth. Samples were stored at $-80^{\circ} \mathrm{C}$ until further processing.

\section{$2.316 S$ rRNA and ITS1 metabarcoding}

DNA was extracted using the DNeasy PowerSoil kit (Qiagen) following the manufacturer's instructions. Metabarcoding libraries were prepared with a two step PCR protocol. For the first PCR reaction, the V4 16S rRNA region was amplified, following Toju et al. (2019), with the forward primer 515f $5^{\prime}$-tcg tcg gca gcg tca gat gtg tat aag aga cag GGT GCC AGC MGC CGC GGT AA-3' and the reverse primer 806R 5'-gtc tcg tgg gct cgg aga tgt gta taa gag aca gGA CTA CHV GGG TWT CTA AT-3', along with artificial overhang sequences (lowercase). For ITS1, the first PCR primers were ITS1_F_KYO2 5'-TAG AGG AAG TAA AAG TCG TAA-3' and ITS2_KYO1 5'-gtc tcg tgg gct cgg aga tgt gta taa gag aca gCT RYG TTC TTC ATC GDT-3' following Toju et al. (2012), with the same overhangs as in the V4 primer. In the second PCR reaction, sample specific barcode sequences and Illumina flow cell adapters were attached, using the forward primer '5-AAT GAT ACG GCG ACC ACC GAG ATC TAC ACt cgt cgg cag cgt cag atg tgt ata aga gac ag-' 3 and the reverse primer '5-CAA GCA GAA GAC GGC ATA CGA GAT XXX XXX XXg tct cgt ggg ctc gg-'3', including Illumina adapters (uppercase), overhang complementary sequences (lowercase), and sample specific DNA barcodes (' $\mathrm{X}$ ' sequence). The PCR reactions were carried out in triplicate, with the KAPA HiFi HotStart ReadyMix PCR Kit (KAPA biosystems), in a volume of $25 \mu \mathrm{l}$, including $2 \mu \mathrm{l}$ of DNA template and following the manufacturer's instructions. The first PCR reaction started with a denaturation step of 3 minutes at $95{ }^{\circ} \mathrm{C}$, 
followed by 30 cycles of 20 seconds denaturation at $98^{\circ} \mathrm{C}, 15$ seconds of annealing at $55^{\circ} \mathrm{C}$ and 7 seconds polymerization at $72^{\circ} \mathrm{C}$. The reaction was finalized with another minute long polymerization step. The second PCR reaction was carried out in a volume of $25 \mu \mathrm{l}$ as well, with $2 \mu \mathrm{l}$ of the PCR1 product as DNA template. It started with a 3-minutes denaturation step at $95^{\circ} \mathrm{C}$, followed by 8 cycles of 20 seconds denaturation at $98^{\circ} \mathrm{C}, 15$ seconds of annealing at $55^{\circ} \mathrm{C}$ and 7 seconds polymerization at $72^{\circ} \mathrm{C}$. The second PCR reaction was also finalized with another 60-second polymerization step. The first and second PCR reaction products were purified using AMPure XP PCR product cleanup and size selection kit (Beckman Coulter), following the manufacturer's instructions, and normalised based on Quant-iT PicoGreen (Invitrogen) quantifications. The fragment size distribution in the pooled libraries was examined on a TapeStation 4200 (Agilent) and the libraries were sequenced on an iSeq-100 Illumina platform, producing $150 \mathrm{bp}$ paired end reads. Sequence data was deposited in the National Center for Biotechnology Information (NCBI) data bank, under BioProject accession PRJNA697940.

2.4 Data processing, taxonomy assignment and biodiversity analysis

All the analysis carried out for this study is available as a Jupyter notebook in a github repository (GitHub: https://git.io/It4WP, Zenodo DOI: 10.5281/zenodo.4480328), along with the sequence data, intermediate and output files. The bioinformatics analysis was carried out with Qiime2 (Bolyen et al., 2019). DADA2 (Callahan et al., 2016) was used to trim PCR primers, quality-filter, error correct, dereplicate and merge the read pairs, and to remove chimeric sequences, to produce the amplicon sequence variants (ASV). Specific ASVs are referred to by the first four characters of their MD5 digests, which correspond with the biom table headers. For taxonomic assignment, a naive Bayes classifier was trained using taxonomically identified reference sequences from the Silva 138 SSU-rRNA database (Quast et al., 2013) for the V4 fragments and the UNITE Feb 2019 database (Abarenkov et al., 2010) for the ITS1 fragments. All ASVs that were identified as mitochondrial or chloroplast sequences were filtered out from the feature table. The filtered ASV biom table was further filtered to exclude samples with less than 3000 sequences. These cutoffs were determined based on alpha rarefaction curves and represented the lowest read count in the saturated section of the curve. An ASV phylogenetic tree was built with the q2-phylogeny plugin, implementing MAFFT 7.3 (Katoh and Standley, 2013) for sequence alignment, and FastTree 2.1 (Price et al., 2010), with the default masking options. Microbial diversity was estimated based on Faith's phylogenetic diversity (Faith, 1992) for alpha diversity and weighted and unweighted UniFrac distance (Lozupone and Knight, 2005) matrices for beta diversity. Ordination of the beta-diversity distance was carried out with a principal coordinates analysis (PCoA; Halko et al., 2011; Legendre and Legendre, 2012). The effects of the hillslope-type, niche and hillslope on the microbial diversity were tested with a factorial ANOVA using the q2-longitudinal plugin (Bokulich et al., 2017). P-values were corrected for multiple testing using the Benjamini-Hochberg procedure (Benjamini and Hochberg, 1995). Corrected p-values are referred to as q-values throughout the text. 
bioRxiv preprint doi: https://doi.org/10.1101/2021.03.08.434393; this version posted March 16, 2021. The copyright holder for this preprint (which was not certified by peer review) is the author/funder, who has granted bioRxiv a license to display the preprint in perpetuity. It is made available under aCC-BY 4.0 International license.
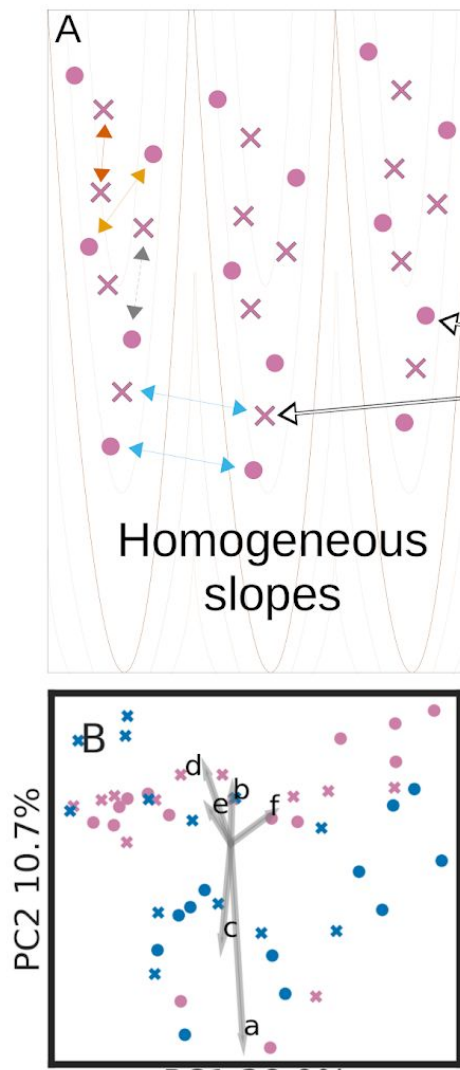

PC1 38.9\%

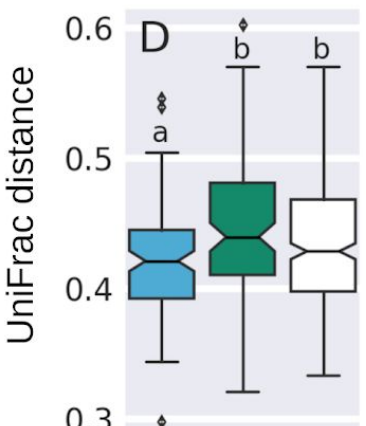

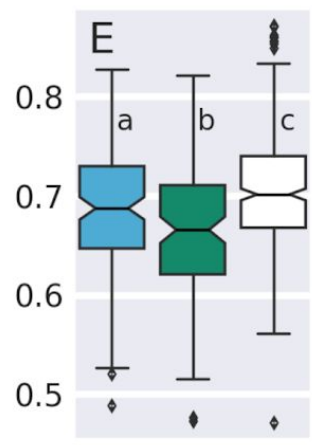

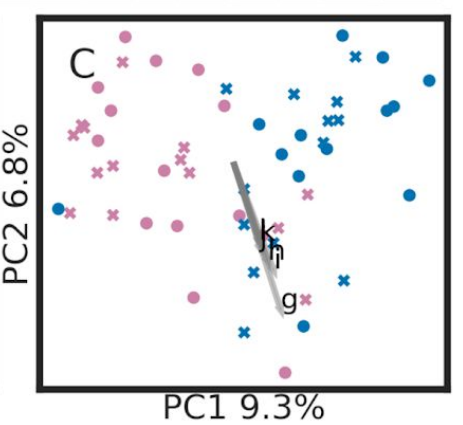

\section{Sample typles}

- Shrubby patch - Heterogeneous XInter patch space - Heterogeneous

Shrubby patch - Homogeneous

$X$ Inter patch space - Homogeneous

Pairwise UniFrac distances within and among niches

Within niche: shrubs (within geodiversity class, within slope)

Within niche: spaces (within geodiversity class, within slope)

Among niche (within geodiversity class, within slope)

Pairwise UniFrac distances within and among geodiversity classes

Within geodiversity class: homogeneous (within niche, among slope)

Within geodiversity class: heterogeneous (within niche, among slope) Among geodiversity class (within niche, among slope)

71e3 uncultured Acidobacterium bdlf Vicinamibacteraceae

c 8ea5 Arenimicrobium_luteum

d dfb4 uncultured Rubrobacter

e 6caa uncultured_actinobacterium

252c Microvirga

649c Geminibasidium

$6 \mathrm{fcf}$ Geminibasidium

49da Stagonosporopsis

Oael Geminibasidium

Oad3 Geminibasidium

040f Geminibasidium
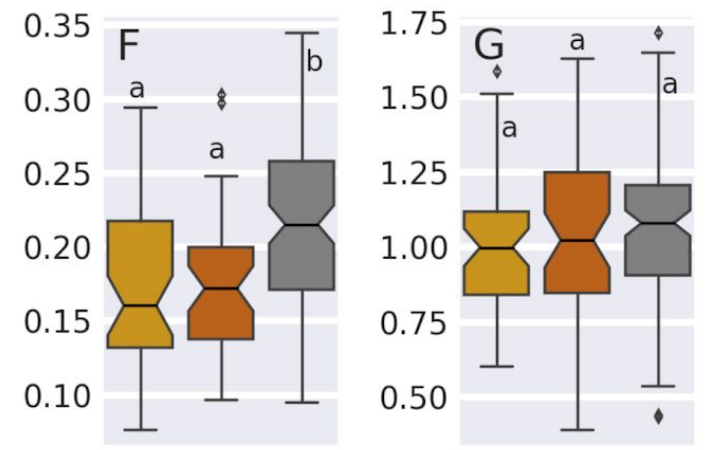

Fig. 1: Investigation of microbial beta-diversity in the study area. Three homogeneous and three heterogeneous hillslopes were selected for this study. In each hillslope, five soil samples were collected from shrubby patches and five from inter-shrub areas (A), all from 8-10 cm depth. Arrows in sub-plot A exemplify the type of sample pairs which were used to calculate pairwise UniFrac distances for the beta diversity factorial ANOVA tests. The sample types are listed in the legend. Beta diversity was first investigated with UniFrac distance matrices and principal coordinate analyses (PCoA). Weighted analysis is presented for bacteria (B) and unweighted for fungi (C). Gray arrows (B and C) represent the six most important ASVs explaining the total variance, following the importance definition of Legendre and Legendre (2012). The identity of the important ASVs are indexed with lowercase letters and listed on the right-hand side. Unweighted UniFrac pairwise distances within and among biodiversity classes are presented as boxplots for prokaryotes (D) and fungi (E). Weighted UniFrac pairwise distances within and among niches are presented as boxplots for bacteria (F) and fungi (G). Within each boxplot (D-G), boxes which share a lowercase letter label represent distance distributions which are not significantly different, whereas boxes denoted with different letters represent distance distributions that are significantly different from each other. 
2.5 Identification of explanatory taxa, ASVs and prokaryotic genes

To identify differentially abundant orders between the homogeneous and heterogeneous hillslopes we collapsed the ASV table to the order level and carried out pairwise Mann-Whitney tests (Mann and Whitney, 1947) between the two classes. As before, p-values were corrected for multiple testing using the Benjamini-Hochberg procedure (Benjamini and Hochberg, 1995). ASVs explaining the total variance of UniFrac distances were identified with a biplot analysis (Legendre and Legendre, 2012). ASV differences between the two hillslope types were investigated with a supervised learning approach based on logistic regression (Yu et al., 2011) using the Scikit-learn package (Pedregosa et al., 2011). Data were equally split between the training and testing sets, and were stratified to equally represent homogeneous and heterogeneous hillslopes in each subset. The procedure was replicated across 100 different random-seeds for the train-test data splitting step. Logistic regression was also used to identify explanatory relative abundance changes of prokaryotic genes, between the two geodiversity classes. 16S rRNA based metagenome reconstruction was carried out with PiCRUST2 (Langille et al., 2013).

\section{Results}

We obtained 55 samples with a median coverage of 7679 reads for the V4 fragment and 54 samples with a median coverage of 8847 reads for the ITS1 fragment, after the exclusion of low quality, chimeric and organelle sequences, and low coverage samples $<3000$ post-filtration read-pairs). The prokaryote and fungal orders with the highest average relative abundances are presented in Fig. 2. On average, the most abundant bacterial orders were
Rubrobacterales $\quad(0.12$ and 0.09 for heterogeneous and homogeneous hillslopes, respectively), Vicinamibacterales $(0.1$ and 0.096), Pyrinomonadales (0.09 and 0.06), and Rhizobiales (0.07 and 0.08). The most abundant fungal orders were, on average, Pleosporales (0.19 and 0.24), Sordariales (0.15 and 0.07), Mortierellales (0.076 and 0.079) and Xylariales (0.02 and 0.05). On the order level, relative abundances were similar between the two hillsploe types, except for the bacterial orders Micrococcales and Burkholderiales, and the fungal order Chaetothyriales (q-value $<0.05$ ).

\subsection{Microbial diversity}

For biodiversity analyses we rarefied all the samples to 3000 reads post-filtration, following the guidance of rarefaction curves (Fig. S1), which indicated that rare taxa were sufficiently represented. The Faith-PD metric (Faith, 1992), accounting for the number of amplicon sequence variants (ASVs), their relative proportions and their phylogenetic relationships, was used to describe alpha diversity. According to a factorial ANOVA accounting for the geodiversity levels (heterogeneous vs. homogeneous) and the niche (shrubby patch vs. inter-shrub), neither factor had significant effects on prokaryotes or fungi.

Unlike alpha diversity, beta diversity, expressed as pairwise UniFrac distances (Lozupone and Knight, 2005), was affected by hillslope type. In a principal coordinates analysis (PCoA; Legendre and Legendre, 2012) based on the bacterial weighted UniFrac matrix (Fig. 1B), geodiversity classes appeared to be partially segregated along the second axis, which explained $10.7 \%$ of the total variance. The beta diversity of fungi was also partially explained by hillslope type, based on the first axis of an unweighted UniFrac PCoA analysis (Fig. 1C, $9.3 \%$ of the variance). 

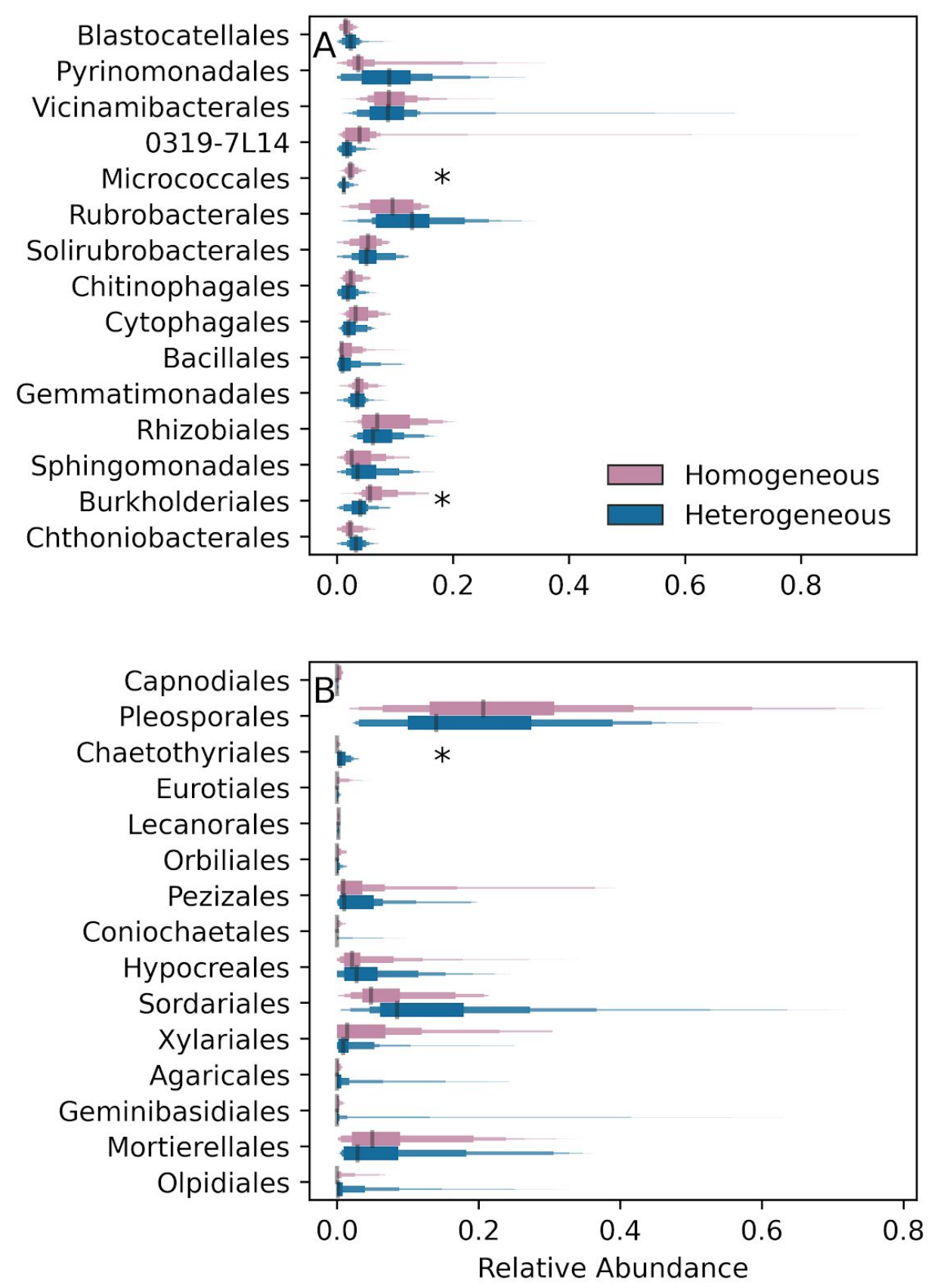

Fig. 2: Order level relative abundance distributions in prokaryotes (A) and fungi (B). * - Significant difference between homogeneous and heterogeneous hillslopes according to Mann Whitney U-test

To formally test whether the hillslope type significantly explained beta diversity, we carried out a factorial ANOVA test, in which the within-homogeneous hillslopes pairwise UniFrac distances, the within-heterogeneous hillslopes pairwise UniFrac distances and between hillslope-type distances were considered as levels. Only distances between pairs of samples belonging to the same niche were considered. For prokaryotes, differences among the unweighted UniFrac distance distributions (Fig. 1D) were significantly 
explained by the hillslope type (p-value < 0.0067), a pattern which was marginally more pronounced in inter-shrub spaces than in shrubby patches $(\mathrm{p}$-value $=0.02)$. Distances were smaller within the homogeneous hillslopes than within the heterogeneous hillslopes (q-value < 0.0061), and marginally smaller within the homogeneous hillslopes than between the hillslope type (q-value < 0.024), indicating that the homogeneous hillslopes might be more selective or restrictive for prokaryotes. Weighted pairwise distances were not explained by hillslope type in prokaryotes, indicating that the observed pattern was due to differences in taxa and not due to differences in their relative abundances.

In fungi, hillslope type significantly explained pairwise unweighted distances as well (p-value $<1.5 \times 10^{-9}$ ), without difference between the niches (shrub patches vs. inter-patch spaces; p-value $=0.9$ ). For fungi, it was the heterogeneous hillslopes that had the smallest pairwise distances (Fig. 1E; q-value < 0.0036 and q-value $<1.3 \times 10^{-9}$ ), but homogeneous hillslopes pairwise-distances were also smaller than between hillslope-type distances (q-value < 0.004). Weighted pairwise distances were less significantly explained by hillslope type (p-value $=0.005$ ) than the unweighted distances ( $\mathrm{p}$-value $<1.5 \times 10^{-9}$ ), indicating again that the difference in the taxa between the heterogeneous and homogeneous hillslopes was more important than the differences in their relative abundances.

We similarly tested the niche effect on beta diversity, considering only within hillslope-type distances. For prokaryotes, weighted pairwise distances within the niches were smaller than between the niches ( $p$-value < $5 \times 10-6$; Fig. 1F), an effect evident in both homogeneous and heterogeneous hillslopes
( $\mathrm{p}$-value $=0.2)$. The effect was smaller when considering unweighted distances (p-value < 0.007), indicating that changes in relative abundances rather than in the taxa themselves were the key difference between the niches. Interestingly, niche differences generated negligible effects for fungi (Fig. 1G; p-value $=0.2$ for weighted-UniFrac and $p$-value $=0.05$ for unweighted UniFrac distances).

\subsection{Explanatory ASVs - total variance}

Explanatory taxa were investigated with BiPlot analyses (Legendre and Legendre, 2012) to identify the taxa explaining the total variance and with logistic regression classifications (Yu et al., 2011) and the ANCOM procedure (Mandal et al., 2015) to identify the taxa that diverged between the homogeneous and heterogeneous hillslopes. The most important bacterial ASVs for the total variance, following the importance definition of Legendre and Legendre (2012; Fig. 1B - biplot arrows) were Acidobacterium (ASV 71e3), Arenimicrobium luteum (ASV 8ea5), Vicinamibacteraceae sp. (ASV 6d1f) and Rubrobacter sp. (ASV dfb4). These ASVs aligned with the second PCoA axis (Fig. 1B). Thus, Acidobacterium (ASV 71e3) and Arenimicrobium luteum (ASV 8ea5) were usually more abundant in the heterogeneous hillslopes while Vicinamibacteraceae sp. (ASV 6d1f) and Rubrobacter sp. (ASV dfb4) were usually more abundant in the homogeneous hillslopes, but were obviously affected by factors other than geodiversity or niche. For fungi, the most important taxa explaining the total variance (Fig. 1C, biplot arrows) were three Geminibasidium sp. ASVs (649c, 6fcf and 0ae1) and one Stagonosporopsis sp. ASV (49da), but their abundance was not shaped by the hillslope type or niche differences. 
bioRxiv preprint doi: https://doi.org/10.1101/2021.03.08.434393; this version posted March 16, 2021. The copyright holder for this preprint (which was not certified by peer review) is the author/funder, who has granted bioRxiv a license to display the preprint in perpetuity. It is made available under aCC-BY 4.0 International license.
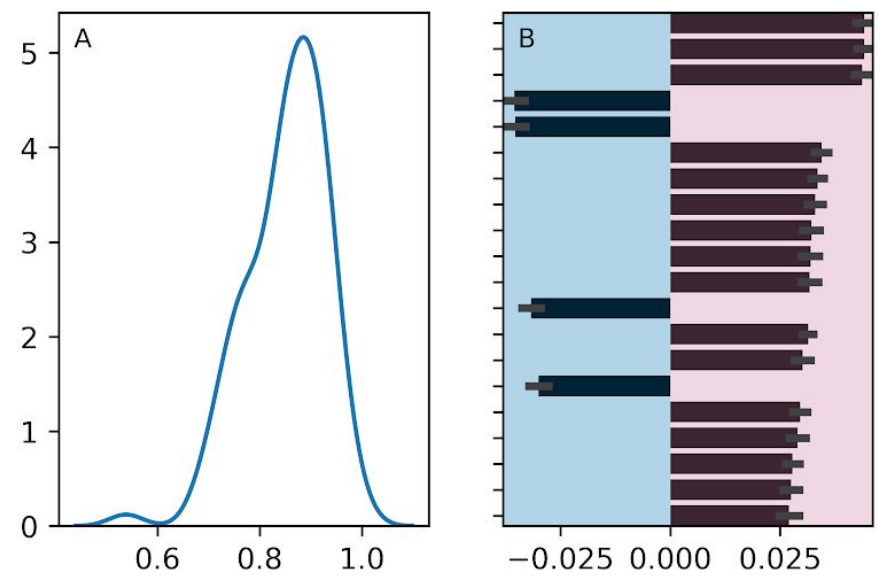

$-0.0250 .000 \quad 0.025$
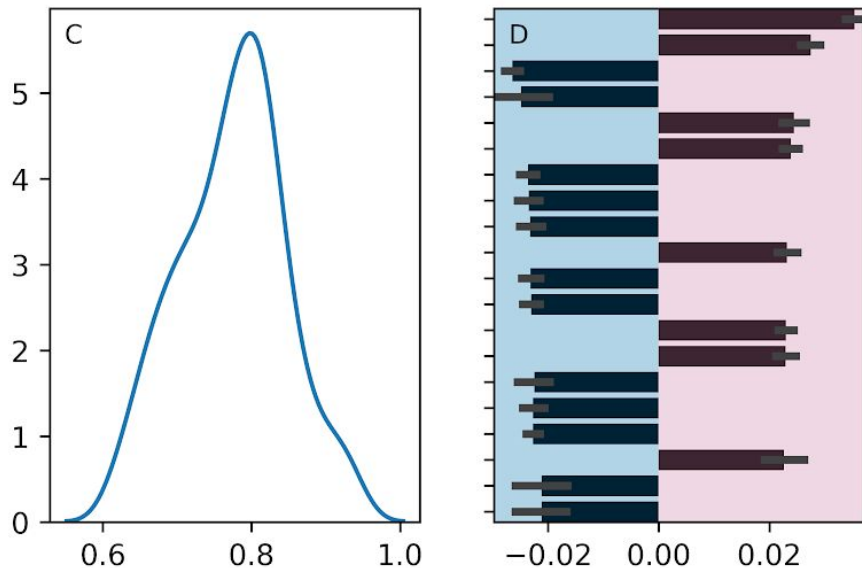

9256 Ascomycota*

3876 Ascomycota*

$8 \mathrm{fgf}$ Ascomycota

bf22 Microascaceae

ff77 Sordariomycetes 6030 Ascomycota*

5541 Lecanoromycetesł

48c2 Thielavia inaequalis ${ }^{\wedge}$

89c0 Ascomycota

3422 Sordariales

eb11 Ascomycotał

028e Chaetomiaceae

$07 \mathrm{~b} 5$ Ascomycota*

e603 Ascomycota*

4ead Thielavia inaequalis ${ }^{\wedge}$

a4fe Chaetomiaceae ${ }^{\wedge}$

9966 Ascomycotat

82 b7 Sordariomycetes\$

$3 a 8 f$ Hypocreales

7b3d Ascomycota
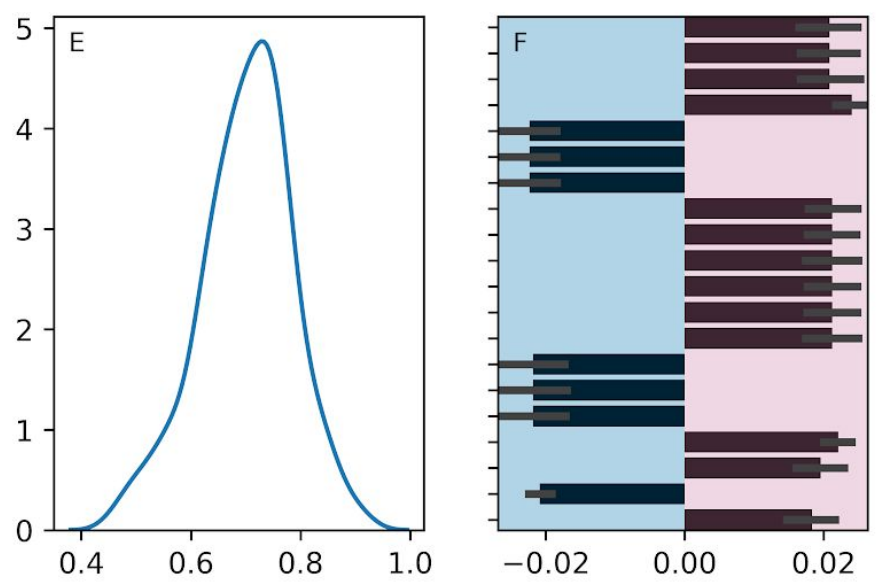

K06922

BCS1

E2.1.3.1-12S

nagC

rif14

KDSR

DHRS13

mvhD, vhuD, vhcD

vorA

MvhA, vhuA, vhcA

mvhG, vhuG, vhcG

AGPAT1 2

vorB

MTHFD

ptcA

K09138

TC.DCUC, dcuC, dcuD

DUG3

ECE

$\begin{array}{lll}-0.02 & 0.00 & 0.02\end{array}$

Fig. 3. Explanatory taxa and bacterial genes. The distribution of $R^{2}(\mathrm{~A}, \mathrm{C}$ and $\mathrm{E})$, and the coefficients with the largest absolute size $(B, D, C)$ resulting from logistic regressions of bacterial relative abundances (A and $\mathrm{B}$ ), fungal relative abundances (C and D) and bacterial genes (E and F) between the two hillslope types. A $R^{2}$ distribution was generated in each regression by repeating the analysis for 100 randomly split training and testing datasets. In all iterations, geodiversity was equally stratified in the training and testing sets. Taxonomic and phylogenetic insights from Fig. S2: *-Monophyletic and assigned to Phaeosphaeriaceae. \$-Hypocreales. ^^-Monophyletic Thielavia inaequalis. †-Monophyletic Ascomycota. ‡-Monophyletic Lecanoromycetes. 
3.3 Explanatory ASVs and prokaryotic genes homogeneous vs. heterogeneous hillslopes

According to a logistic regression, prokaryote relative abundances were well explained by the hillslope type (Fig. 3A; mode $R^{2}=0.89$ ). Out of the 20 taxa that best explained the regression (Fig. 3B), ASVs which were best associated with a homogeneous-hillslope classification included Vicinamibacteraceae sp. (691f; order Vicinamibacterales), Arthrobacter sp. (fe74; Micrococcales), Bacteroidetes sp. (fdc0; Cytophagales), Nitrosomonadaceae - NMD1 (b2fa; Burkholderiales), Nitrosococcaceae sp. wb1-P19 (a360; Nitrosococcales), Chitinophagaceae sp. (bfa2; Chitinophagales), Burkholderiaceae sp. (e5df; Burkholderiales), Gemmatimonas sp. (24b7; Gemmatimonadales), Nitrososphaeraceae sp. (cd0b, 1505; Nitrososphaerales), Acidimicrobiia-IMCC26256 sp. (6946), Adhaeribacter sp. (c3a1; Cytophagales), Microvirga sp. (87e5; Rhizobiales), Chthoniobacter sp. (de3f; Chthoniobacterales), Actinobacteria 0319-7L14 (40e8) and Solirubrobacterales 67-14 (5fe9). The higher relative abundance of Vicinamibacteraceae sp. (691f) in homogeneous hillslopes was also supported by the ANCOM test. Many of these taxa are cellobiose degrading aerobes (Huber and Overmann, 2019a, 2019b, 2018; Janssen, 2015; Jones and Keddie, 2006; Kämpfer et al., 2011; Reichenbach, 1992; Zhang et al., 2019), whose increase may cause a shift in the soil's redox properties, as cellobiose is a reducing sugar (Schellenberger et al., 2011). Ammonia oxidizers (Holmes et al., 2001; Prosser et al., 2014) and iron oxidizers (Hu et al., 2018) are also a striking component of this cohort. Prokaryote taxa that were best associated with a heterogeneous hillslope classification were Pyrinomonadaceae sp. - RB41 (3351, 9fe6, 7254; Pyrinomonadales) and Rubrobacter sp. (1649; Rubrobacterales). Of these taxa, only
Rubrobacter sp. degrades cellobiose (Albuquerque et al., 2014; Wüst et al., 2016).

A good fit to hillslope type was obtained for fungal relative abundances as well (Fig. 3C; mode $R^{2}=0.8$ ), with five Ascomycota ASVs (9256, 3876, 6030, 07b5, e603), which were monophyletic and assigned to Phaeosphaeriaceae according to a phylogenetic analysis (Fig. S2), along with a Sordariomycetes sp. ASV (ff77), Sordariales sp. (3422; Sordariomycetes) and another Sordariomycetes ASV (82b7; Hypocreales sp. according to Fig. S2), were best associated with a homogeneous hillslope classification. The higher relative abundance of Phaeosphaeriaceae (Ascomycota ASV 9256) in homogeneous hillslopes was also supported by an ANCOM test. Phaeosphaeriaceae and Sordariomycetes are associated with plant pathogens and saprobes (Maharachchikumbura et al., 2015; Phookamsak et al., 2014). Conversely, three distinct Ascomycota sp. ASVs (8f9f, 89c0, 7b3d), Microascaceae sp. ASV (bf22; Microascales), two monophyletic Lecanoromycetes sp. ASVs (5541; eb11, Fig. S2), four Thielavia inaequalis ASVs (48c2, 028e, 4ead, a4fe; Sordariales, Fig. S2) and another Hypocreales sp. (3a8f), were best associated with a heterogeneous hillslope classification. An order level ANCOM test also supported the higher relative abundance of Chaetothyriales in heterogeneous hillslopes. Microascaceae (Sandoval-Denis et al., 2016), Chaetothyriales (Teixeira et al., 2017), Hypocreales (Maharachchikumbura et al., 2015) and Thielavia inaequalis (Srivastava et al., 1966) are associated with plant and/or vertebrate pathogens or decomposers, like fungi of the homogeneous hillslopes. However, Lecanoromycetes, which contain most of the lichen forming fungi (Miadlikowska et al., 2006), represent a very different functional group. To comment on possible artifacts in our ITS1 phylogenetic analysis (Fig. S2), monophyletic 
ASVs were manually inspected to confirm that the sequence divergence was genuine and not an ASV assembly artifact. Intraspecific divergence of ITS sequences in fungi was previously reported (Nilsson et al., 2008).

The fit of prokaryotic genes' relative abundances, as reconstructed by PiCRUST2 (Langille et al., 2013), with the hillslope type, was lower than that of taxonomic relative abundances (Fig. 3E; mode $R^{2}=0.72$ ). Genes which were best associated with a homogeneous hillslope classification (Fig. 3F) included BCS1, a microbial $12 \mathrm{~S}$ subunit protein, nagC, $\mathrm{mvhD}$, vorA, mvhA, mvhG, AGPAT1_2, DCUC, DUG3 and glcG. They are involved in aerobic breathing and the tricarboxylic acid cycle (Hou et al., 2015; Janausch et al., 2002), disaccharide degradation (El Qaidi and Plumbridge, 2008), F420 oxidation (Stojanowic et al., 2003) and Ferredoxin activity (Charon et al., 1999). Conversely, rif14, KDSR, DHRS13, MTHFD, ptcA and ECE were best associated with a heterogeneous hillslope classification. The rif14 gene is a part of the Rifamycin B production pathway (Xu et al., 2003), DHRS13 is involved in the production of extracellular superoxides (Diaz et al., 2013), also promoted by the reduction of NADP+ (Diaz et al., 2013) by MTHFD (Röttig and Steinbüchel, 2013). KDSR is involved in sphingolipid metabolism in membranes of some anaerobes (Olsen and Jantzen, 2001). The gene ptcA is involved in putrescine metabolism and in one of the metabolic pathways producing gamma-aminobutyric acid (Chen et al., 2011; Jorge et al., 2017).

\section{Discussion}

In order to understand the functioning of ecosystems, it is important to account for the spatial structure of microbial communities. This structure is directly connected to spatial changes in turnover rates of many microbially mediated processes. More often than not, microbial communities and their functions are compared among different ecosystems (Nelson et al., 2016; Prober et al., 2015; Tedersoo et al., 2014; Wen et al., 2017), among distinctly different land uses, treatments or host classes (Espenberg et al., 2018; e.g., Giné et al., 2016; Krotman et al., 2020; Sher et al., 2012) or at a millimetric spatial scale, among minute ecological niches and pedology classes (Upton et al., 2019; Yergaliyev et al., 2020). Our study investigated the relationship between the structure of the soil microbial community and geodiversity at a hillslope scale, a few hundred square meters, within a single landform. Recent studies, which tied the hillslope-scale geodiversity variations with shrub mortality in this dryland region (Stavi et al., 2019, 2018a), illustrated that this scale of geodiversity may be an important determinant of microbial diversity.

In this study, we discovered that the hillslope type affected the structure of soil microbial communities. Particularly, the presence and absence of ASVs varied between the two hillslope types. For prokaryotes, the homogeneous hillslope samples were most similar to one another while for fungi, heterogeneous hillslopes were most similar to one another. This result may indicate that the magnitude of ecological drift (sensu Gilbert and Levine, 2017) was inverse for fungi and prokaryotes, as follows. Conditions were more restrictive to prokaryotic diversity in the homogeneous hillslopes and for fungi in the heterogeneous hillslopes, whereas the stochasticity of processes shaping the community was higher for prokaryotes in heterogeneous hillslopes and for fungi in the homogeneous hillslopes. Notably, albeit significant, the observed differences were small and we cannot attest to their dynamics.

Using logistic-regression analyses, we attempted to understand whether the increased 
prokaryotic diversity and reduced fungal diversity in the heterogeneous hillslopes are beneficial in terms of regulatory ecosystem services, particularly with regards to plants. A very consistent difference in the presence and absence of prokaryotic ASVs was observed between the two hillslope types (mode $\mathrm{R}^{2}=$ 0.89), which displayed a striking increase in cellobiose degrading aerobes in the homogeneous hillslopes, along with an increase in ammonia oxidizers. This suggests that the homogenous soil community is less favorable for plants because they harm the ammonia supply by actively oxidizing it and by shifting the redox potential in the soil. Various oxidative activities and disaccharide degradation were also observed among the bacterial genes associated with homogeneous hillslopes. The functional analysis also indicated that heterogeneous hillslope taxa were more active in the deterrence of pathogens, with antibiotics and superoxide production. Possibly, they were also more active in the production of gamma-aminobutyric acid (GABA). In plants, GABA is at the crossroad of several biotic and abiotic stress response mechanisms, including the production of succinic acid and lactic acid. Succinic acid, in turn, promotes energy production through the maintenance of the tricarboxylic acid cycle, often inhibited in stress conditions (Li et al., 2017; Shelp et al., 2017). An exogenous source of GABA was shown to increase the concentration of both endogenous GABA and succinic acid (Hijaz and Killiny, 2019). To summarize, it would seem that homogeneous-hillslope prokaryotic communities reduce ammonia availability and provide less pathogen response mechanisms, and are therefore detrimental to plants, in comparison with the communities of heterogeneous hillslopes.

Interestingly, the inverse pattern observed for fungi, wherein the fungal beta diversity was higher in the homogeneous hillslopes, could also be interpreted as being associated with the improved vigor of plants in the heterogeneous hillslopes. According to the logistic regression analysis of fungal relative abundances (mode $\mathrm{R}^{2}=0.8$ ), the increased diversity in homogeneous hillslopes can be attributed to plant pathogens and saprobes. The main functional difference between the two geodiversity classes that can be inferred from this analysis is the loss of Lecanoromycetes in the homogeneous hillslopes, which contain most lichenised fungi. Epilithic lichens play a role in the regulation of soil-water dynamics, as they intercept raindrops and allow slow release of the absorbed water (Zedda and Rambold, 2015). In water-limited habitats this could be crucial for the performance of plants.

Key questions that require further study relate to the soil-water threshold beyond which heterogeneous hillslopes can no longer maintain a supportive microbial community for plants, and the temporal stability of the observed patterns. Some insight can be gained from a study that compared soil microbial functions between live and dead shrub patches in the Sayeret Shaked LTER station, at the onset of shrub mortality (Sher et al., 2012). The researchers reported a higher ammonia oxidation potential under the canopies of dead N. mucronata shrubs than under live plants. According to Stavi et al. $(2019,2018 a), \quad N$. mucronata mortality was spatially associated with low geodiversity. Therefore, there is an agreement between their observations and ours. Sher et al. (2012) also suggested that the lack of soil-water, which brought about aerobic conditions, could explain the increase in ammonia oxidation and reduced denitrification under drought conditions, which corresponds with our observations of increased abundances of ammonia oxidizing bacteria in the homogeneous, more aerated, hillslopes. 
Therefore, the comparison between Sher et al. (2012) and the current study provides some evidence for the persistence of microbial diversity patterns during the prolonged drought episode.

\section{Conclusion}

Hillslope geodiversity is an important determinant, not only of plant diversity but also of microbial diversity. Interestingly, our results suggest that the positive effect of high geodiversity on shrub vigor is not limited to direct actions of abiotic factors. Microbially conferred regulatory ecosystem services that facilitate shrub survival are also positively affected. Compared with the heterogeneous hillslopes, the deterioration of the shrub community in homogeneous hillslopes occurs not only due to the direct effect of reduced soil-water storage, but also through the shift in microbial community, caused by the same degraded soil-water conditions.

\section{CRediT authorship contribution statement}

A. Szitenberg: Investigation, Formal analysis, Validation, Visualization, Writing - original draft, Funding acquisition, Resources. R. Alexander-Shani: Investigation, Resources. Hezi Yizhak: Conceptualization. I. Stavi: Conceptualization, Investigation, Writing review \& editing, Funding acquisition.

\section{Data statement}

The authors confirm that the data supporting the findings of this study are available under

\section{References}

Abarenkov, K., Henrik Nilsson, R., Larsson, K.-H., Alexander, I.J., Eberhardt, U., Erland, S., Høiland, K., Kjøller, R., Larsson, E., Pennanen, T., Others, 2010. The UNITE
BioProject PRJNA697940 and Zenodo DOI: 10.5281/zenodo.4480328.

\section{Funding statement}

This work was supported by ICA in Israel, grant 03-20-09 to AS and the Israel Science Foundation, grant 1260/15 to IS. The Dead Sea and Arava Science Center is supported by the Ministry of Science and Technology, Israel.

\section{Declaration of competing interest}

The authors declare that they have no known competing financial interests or personal relationships that influenced the work reported in this paper

\section{Acknowledgements}

The authors thank Michelle Finzi for English language editing of the manuscript. This publication is based upon work from COST Action G-Bike (CA18134), supported by COST (European Cooperation in Science and Technology).

\section{Appendix. Supplementary data}

Fig. S1: 16S rRNA and ITS1 rarefaction curves

https://doi.org/10.6084/m9.figshare.13669100 Fig. S2: ITS1 ASV phylogeny. ASV sequences have red labels and reference sequences (black) are from the UNITE database. Bullets at node bases represent a $65 \%$ bootstrap support or higher.

https://doi.org/10.6084/m9.figshare.13669106

database for molecular identification of fungi-recent updates and future perspectives. New Phytol. 186, 281-285.

Albuquerque, L., Johnson, M.M., Schumann, P., Rainey, F.A., da Costa, M.S., 2014. 
Description of two new thermophilic species of the genus Rubrobacter, Rubrobacter calidifluminis sp. nov. and Rubrobacter naiadicus sp. nov., and emended description of the genus Rubrobacter and the species Rubrobacter bracarensis. Syst. Appl. Microbiol. 37, 235-243.

Beier, C., Beierkuhnlein, C., Wohlgemuth, T., Penuelas, J., Emmett, B., Körner, C., de Boeck, H., Christensen, J.H., Leuzinger, S., Janssens, I.A., Hansen, K., 2012. Precipitation manipulation experiments challenges and recommendations for the future. Ecol. Lett. 15, 899-911.

Benjamini, Y., Hochberg, Y., 1995. Controlling the false discovery rate: a practical and powerful approach to multiple testing. J. R. Stat. Soc. B 57, 289-300.

Bitan, A., Rubin, S., 1991. Climatic atlas of Israel for physical and environmental planning and design. Ministry of Transport, Jerusalem.

Bokulich, N.A., Zhang, Y., Dillon, M., Rideout, J.R., Bolyen, E., Li, H., Albert, P.S., Gregory Caporaso, J., 2017. q2-longitudinal: a QIIME 2 plugin for longitudinal and paired-sample analyses of microbiome data. Cold Spring Harbor Laboratory. https://doi.org/10.1101/223974

Bolyen, E., Rideout, J.R., Dillon, M.R., Bokulich, N.A., Abnet, C.C., Al-Ghalith, G.A., Alexander, H., Alm, E.J., Arumugam, M., Asnicar, F., Bai, Y., Bisanz, J.E., Bittinger, K., Brejnrod, A., Brislawn, C.J., Brown, C.T., Callahan, B.J., Caraballo-Rodríguez, A.M., Chase, J., Cope, E.K., Da Silva, R., Diener, C., Dorrestein, P.C., Douglas, G.M., Durall, D.M., Duvallet, C., Edwardson, C.F., Ernst, M., Estaki, M., Fouquier, J., Gauglitz, J.M., Gibbons, S.M., Gibson, D.L., Gonzalez, A., Gorlick, K., Guo, J., Hillmann, B., Holmes, S., Holste, H., Huttenhower, C., Huttley, G.A., Janssen, S., Jarmusch, A.K., Jiang, L., Kaehler, B.D., Kang, K.B., Keefe, C.R., Keim, P., Kelley, S.T., Knights, D., Koester, I., Kosciolek, T., Kreps, J., Langille, M.G.I., Lee, J., Ley, R., Liu, Y.-X., Loftfield, E., Lozupone, C., Maher, M.,
Marotz, C., Martin, B.D., McDonald, D., McIver, L.J., Melnik, A.V., Metcalf, J.L., Morgan, S.C., Morton, J.T., Naimey, A.T., Navas-Molina, J.A., Nothias, L.F., Orchanian, S.B., Pearson, T., Peoples, S.L., Petras, D., Preuss, M.L., Pruesse, E., Rasmussen, L.B., Rivers, A., Robeson, M.S., 2nd, Rosenthal, P., Segata, N., Shaffer, M., Shiffer, A., Sinha, R., Song, S.J., Spear, J.R., Swafford, A.D., Thompson, L.R., Torres, P.J., Trinh, P., Tripathi, A., Turnbaugh, P.J., Ul-Hasan, S., van der Hooft, J.J.J., Vargas, F., Vázquez-Baeza, Y., Vogtmann, E., von Hippel, M., Walters, W., Wan, Y., Wang, M., Warren, J., Weber, K.C., Williamson, C.H.D., Willis, A.D., Xu, Z.Z., Zaneveld, J.R., Zhang, Y., Zhu, Q., Knight, R., Caporaso, J.G., 2019. Reproducible, interactive, scalable and extensible microbiome data science using QIIME 2. Nat. Biotechnol. 37, 852-857.

Briske, D.D., Joyce, L.A., Wayne Polley, H., Brown, J.R., Wolter, K., Morgan, J.A., McCarl, B.A., Bailey, D.W., 2015. Climate-change adaptation on rangelands: linking regional exposure with diverse adaptive capacity. Front. Ecol. Environ. 13, 249-256.

Callahan, B.J., McMurdie, P.J., Rosen, M.J., Han, A.W., Johnson, A.J.A., Holmes, S.P., 2016. DADA2: High-resolution sample inference from Illumina amplicon data. Nat. Methods 13, 581-583.

Cartwright, J., 2019. Ecological islands: conserving biodiversity hotspots in a changing climate. Front. Ecol. Environ. 17, 331-340.

Charon, M.H., Volbeda, A., Chabriere, E., Pieulle, L., Fontecilla-Camps, J.C., 1999. Structure and electron transfer mechanism of pyruvate:ferredoxin oxidoreductase. Curr. Opin. Struct. Biol. 9, 663-669.

Chen, J., Cheng, C., Xia, Y., Zhao, H., Fang, C., Shan, Y., Wu, B., Fang, W., 2011. Lmo0036, an ornithine and putrescine carbamoyltransferase in Listeria monocytogenes, participates in arginine deiminase and agmatine deiminase pathways and mediates acid tolerance. Microbiology 157, 3150-3161. 
Diaz, J.M., Hansel, C.M., Voelker, B.M., Mendes, C.M., Andeer, P.F., Zhang, T., 2013. Widespread production of extracellular superoxide by heterotrophic bacteria. Science 340, 1223-1226.

Díaz, S., Settele, J., Brondízio, E.S., Ngo, H.T., Agard, J., Arneth, A., Balvanera, P., Brauman, K.A., Butchart, S.H.M., Chan, K.M.A., Garibaldi, L.A., Ichii, K., Liu, J., Subramanian, S.M., Midgley, G.F., Miloslavich, P., Molnár, Z., Obura, D., Pfaff, A., Polasky, S., Purvis, A., Razzaque, J., Reyers, B., Chowdhury, R.R., Shin, Y.-J., Visseren-Hamakers, I., Willis, K.J., Zayas, C.N., 2019. Pervasive human-driven decline of life on Earth points to the need for transformative change. Science 366. https://doi.org/10.1126/science.aax3100

Dijkstra, F.A., He, M., Johansen, M.P., Harrison, J.J., Keitel, C., 2015. Plant and microbial uptake of nitrogen and phosphorus affected by drought using $15 \mathrm{~N}$ and $32 \mathrm{P}$ tracers. Soil Biol. Biochem. 82, 135-142.

El Qaidi, S., Plumbridge, J., 2008. Switching control of expression of ptsG from the Mlc regulon to the NagC regulon. J. Bacteriol. 190, 4677-4686.

Espenberg, M., Truu, M., Mander, Ü., Kasak, K., Nõlvak, H., Ligi, T., Oopkaup, K., Maddison, M., Truu, J., 2018. Differences in microbial community structure and nitrogen cycling in natural and drained tropical peatland soils. Sci. Rep. 8, 4742.

Faith, D.P., 1992. Conservation evaluation and phylogenetic diversity. Biol. Conserv. 61, 1-10.

Gilbert, B., Levine, J.M., 2017. Ecological drift and the distribution of species diversity. Proc. Biol. Sci. 284. https://doi.org/10.1098/rspb.2017.0507

Giné, A., Carrasquilla, M., Martínez-Alonso, M., Gaju, N., Sorribas, F.J., 2016. Characterization of soil suppressiveness to root-knot nematodes in organic horticulture in plastic greenhouse. Front. Plant Sci. 7, 164.

Gray, M., 2005. Geodiversity and geoconservation: What, why, and how? George Wright Forum 22, 4-12.
Halko, N., Martinsson, P., Shkolnisky, Y., Tygert, M., 2011. An algorithm for the principal component analysis of large data sets. SIAM J. Sci. Comput. 33, 2580-2594.

Hijaz, F., Killiny, N., 2019. Exogenous GABA is quickly metabolized to succinic acid and fed into the plant TCA cycle. Plant Signal. Behav. 14, e1573096.

Holmes, A.J., Tujula, N.A., Holley, M., Contos, A., James, J.M., Rogers, P., Gillings, M.R., 2001. Phylogenetic structure of unusual aquatic microbial formations in Nullarbor caves, Australia. Environ. Microbiol. 3, 256-264.

Hoover, D.L., Knapp, A.K., Smith, M.D., 2014. Resistance and resilience of a grassland ecosystem to climate extremes. Ecology 95, 2646-2656.

Hou, J., Xiang, H., Han, J., 2015. Propionyl coenzyme A (propionyl-CoA) carboxylase in Haloferax mediterranei: indispensability for propionyl-CoA assimilation and impacts on global metabolism. Appl. Environ. Microbiol. 81, 794-804.

Huber, K.J., Overmann, J., 2018. Vicinamibacteraceae fam. nov., the first described family within the subdivision 6 Acidobacteria. Int. J. Syst. Evol. Microbiol. 68, 2331-2334.

Huber, K.J., Overmann, J., 2019a. Luteitalea, in: Bergey's Manual of Systematics of Archaea and Bacteria. John Wiley \& Sons, Ltd, Chichester, UK, pp. 1-5.

Huber, K.J., Overmann, J., 2019b. Vicinamibacter, in: Bergey's Manual of Systematics of Archaea and Bacteria. John Wiley \& Sons, Ltd, Chichester, UK, pp. 1-5.Hu, D., Cha, G., Gao, B., 2018. A phylogenomic and molecular markers based analysis of the class Acidimicrobiia. Front. Microbiol. 9, 987.https://doi.org/10.2136/vzj2012.0186

Ibáñez, J.J., Krasilnikov, P.V., Saldana, A., 2012. Archive and refugia of soil organisms: applying a pedodiversity framework for the conservation of biological and non-biological heritages. J. Appl. Ecol. 49, 1267-1277.

Ibáñez, J.J., Feoli, E., 2013. Global relationships of pedodiversity and biodiversity. Vadose 
Zone J. 12.

Janausch, I.G., Zientz, E., Tran, Q.H., Kröger, A., Unden, G., 2002. C4-dicarboxylate carriers and sensors in bacteria. Biochim. Biophys. Acta 1553, 39-56.

Janion-Scheepers, C., Measey, J., Braschler, B., Chown, S.L., Coetzee, L., Colville, J.F., Dames, J., Davies, A.B., Davies, S.J., Davis, A.L.V., Dippenaar-Schoeman, A.S., Duffy, G.A., Fourie, D., Griffiths, C., Haddad, C.R., Hamer, M., Herbert, D.G., Hugo-Coetzee, E.A., Jacobs, A., Jacobs, K., van Rensburg, C.J., Lamani, S., Lotz, L.N., Louw, S.V., Lyle, R., Malan, A.P., Marais, M., Neethling, J.-A., Nxele, T.C., Plisko, D.J., Prendini, L., Rink, A.N., Swart, A., Theron, P., Truter, M., Ueckermann, E., Uys, V.M., Villet, M.H., Willows-Munro, S., Wilson, J.R.U., 2016. Soil biota in a megadiverse country: Current knowledge and future research directions in South Africa. Pedobiologia 59, 129-174.

Janssen, P.H., 2015. Chthoniobacter, in: Bergey's Manual of Systematics of Archaea and Bacteria. Wiley, pp. 1-2.

Jones, D., Keddie, R.M., 2006. The genus Arthrobacter, in: Dworkin, M., Falkow, S., Rosenberg, E., Schleifer, K.-H., Stackebrandt, E. (Eds.), The Prokaryotes. Springer, New York, pp. 945-960.

Jorge, J.M.P., Nguyen, A.Q.D., Pérez-García, F., Kind, S., Wendisch, V.F., 2017. Improved fermentative production of gamma-aminobutyric acid via the putrescine route: Systems metabolic engineering for production from glucose, amino sugars, and xylose. Biotechnol. Bioeng. 114, 862-873.

Kämpfer, P., Lodders, N., Falsen, E., 2011. Hydrotalea flava gen. nov., sp. nov., a new member of the phylum Bacteroidetes and allocation of the genera Chitinophaga, Sediminibacterium, Lacibacter, Flavihumibacter, Flavisolibacter, Niabella, Niastella, Segetibacter, Parasegetibacter, Terrimonas, Ferruginibacter, Filimonas and Hydrotalea to the family Chitinophagaceae fam. nov. Int. J. Syst. Evol. Microbiol. 61, 518-523.
Katoh, K., Standley, D.M., 2013. MAFFT multiple sequence alignment software version 7: improvements in performance and usability. Mol. Biol. Evol. 30, 772-780.

Kreyling, J., Beier, C., 2013. Complexity in climate change manipulation experiments. Bioscience 63, 763-767.

Krotman, Y., Yergaliyev, T.M., Alexander Shani, R., Avrahami, Y., Szitenberg, A., 2020. Dissecting the factors shaping fish skin microbiomes in a heterogeneous inland water system. Microbiome 8, 9 .

Langille, M.G.I., Zaneveld, J., Caporaso, J.G., McDonald, D., Knights, D., Reyes, J.A., Clemente, J.C., Burkepile, D.E., Vega Thurber, R.L., Knight, R., Beiko, R.G., Huttenhower, C., 2013. Predictive functional profiling of microbial communities using 16S rRNA marker gene sequences. Nat. Biotechnol. 31, 814-821.

Legendre, P., Legendre, L., 2012. Numerical Ecology, third. ed. Elsevier, London.

Li, Z., Yu, J., Peng, Y., Huang, B., 2017. Metabolic pathways regulated by abscisic acid, salicylic acid and $\gamma$-aminobutyric acid in association with improved drought tolerance in creeping bentgrass (Agrostis stolonifera). Physiol. Plant. 159, 42-58.

Lozupone, C., Knight, R., 2005. UniFrac: a new phylogenetic method for comparing microbial communities. Appl. Environ. Microbiol. 71, 8228-8235.

Maharachchikumbura, S.S.N., Hyde, K.D., Jones, E.B.G., McKenzie, E.H.C., Huang, S.-K., Abdel-Wahab, M.A., Daranagama, D.A., Dayarathne, M., D’souza, M.J., Goonasekara, I.D., Hongsanan, S., Jayawardena, R.S., Kirk, P.M., Konta, S., Liu, J.-K., Liu, Z.-Y., Norphanphoun, C., Pang, K.-L., Perera, R.H., Senanayake, I.C., Shang, Q., Shenoy, B.D., Xiao, Y., Bahkali, A.H., Kang, J., Somrothipol, S., Suetrong, S., Wen, T., Xu, J., 2015. Towards a natural classification and backbone tree for Sordariomycetes. Fungal Divers. 72, 199-301.

Mandal, S., Van Treuren, W., White, R.A., Eggesbø, M., Knight, R., Peddada, S.D., 2015. Analysis of composition of microbiomes: a 
novel method for studying microbial composition. Microb. Ecol. Health Dis. 26, 27663.

Mann, H.B., Whitney, D.R., 1947. On a test of whether one of two random variables is stochastically larger than the other. Ann. Math. Statist. 18, 50-60.

Miadlikowska, J., Kauff, F., Hofstetter, V., Fraker, E., Grube, M., Hafellner, J., Reeb, V., Hodkinson, B.P., Kukwa, M., Lücking, R., Hestmark, G., Otalora, M.G., Rauhut, A., Büdel, B., Scheidegger, C., Timdal, E., Stenroos, S., Brodo, I., Perlmutter, G.B., Ertz, D., Diederich, P., Lendemer, J.C., May, P., Schoch, C.L., Arnold, A.E., Gueidan, C., Tripp, E., Yahr, R., Robertson, C., Lutzoni, F., 2006. New insights into classification and evolution of the Lecanoromycetes (Pezizomycotina, Ascomycota) from phylogenetic analyses of three ribosomal RNA- and two protein-coding genes. Mycologia 98, 1088-1103.

Nelson, M.B., Martiny, A.C., Martiny, J.B.H., 2016. Global biogeography of microbial nitrogen-cycling traits in soil. Proc. Natl. Acad. Sci. U.S.A. 113, 8033-8040.

Nilsson, R.H., Kristiansson, E., Ryberg, M., Hallenberg, N., Larsson, K.-H., 2008. Intraspecific ITS variability in the kingdom fungi as expressed in the international sequence databases and its implications for molecular species identification. Evol. Bioinform. Online 4, 193-201.

Okin, G.S., Heras, M.M. las, Saco, P.M., Throop, H.L., Vivoni, E.R., Parsons, A.J., Wainwright, J., Peters, D.P.C., 2015. Connectivity in dryland landscapes: shifting concepts of spatial interactions. Front. Ecol. Environ. $13,20-27$.

Olsen, I., Jantzen, E., 2001. Sphingolipids in Bacteria and Fungi. Anaerobe 7, 103-112.

Pedregosa, F., Varoquaux, G., Gramfort, A., Michel, V., Thirion, B., Grisel, O., Blondel, M., Prettenhofer, P., Weiss, R., Dubourg, V., Vanderplas, J., Passos, A., Cournapeau, D., Brucher, M., Perrot, M., Duchesnay, E., 2011. Scikit-learn: Machine Learning in Python. J. Mach. Learn. Res. 12, 2825-2830.
Phookamsak, R., Liu, J.-K., McKenzie, E.H.C., Manamgoda, D.S., Ariyawansa, H., Thambugala, K.M., Dai, D.-Q., Camporesi, E., Chukeatirote, E., Wijayawardene, N.N., Bahkali, A.H., Mortimer, P.E., Xu, J.-C., Hyde, K.D., 2014. Revision of Phaeosphaeriaceae. Fungal Divers. 68, 159-238.

Price, M.N., Dehal, P.S., Arkin, A.P., 2010. FastTree 2-approximately maximum-likelihood trees for large alignments. PLoS One 5, e9490.

Prober, S.M., Leff, J.W., Bates, S.T., Borer, E.T., Firn, J., Harpole, W.S., Lind, E.M., Seabloom, E.W., Adler, P.B., Bakker, J.D., Cleland, E.E., DeCrappeo, N.M., DeLorenze, E., Hagenah, N., Hautier, Y., Hofmockel, K.S., Kirkman, K.P., Knops, J.M.H., La Pierre, K.J., MacDougall, A.S., McCulley, R.L., Mitchell, C.E., Risch, A.C., Schuetz, M., Stevens, C.J., Williams, R.J., Fierer, N., 2015. Plant diversity predicts beta but not alpha diversity of soil microbes across grasslands worldwide. Ecol. Lett. 18, 85-95.

Prosser, J.I., Head, I.M., Stein, L.Y., 2014. The Family Nitrosomonadaceae, in: Rosenberg, E., DeLong, E.F., Lory, S., Stackebrandt, E., Thompson, F. (Eds.), The Prokaryotes: Alphaproteobacteria and Betaproteobacteria. Springer Berlin Heidelberg, Berlin, Heidelberg, pp. 901-918.

Quast, C., Pruesse, E., Yilmaz, P., Gerken, J., Schweer, T., Yarza, P., Peplies, J., Glöckner, F.0., 2013. The SILVA ribosomal RNA gene database project: improved data processing and web-based tools. Nucleic Acids Res. 41, D590-6.

Read, Q.D., Zarnetske, P.L., Record, S., Dahlin, K.M., Costanza, J.K., Finley, A.O., Gaddis, K.D., Grady, J.M., Hobi, M.L., Latimer, A.M., Malone, S.L., Ollinger, S.V., Pau, S., Wilson, A.M., 2020. Beyond counts and averages: Relating geodiversity to dimensions of biodiversity. Glob. Ecol. Biogeogr. 29, 696-710.

Reichenbach, H., 1992. The Order Cytophagales, in: Balows, A., Trüper, H.G., Dworkin, M., Harder, W., Schleifer, K.-H. (Eds.), The 
Prokaryotes: A Handbook on the Biology of Bacteria: Ecophysiology, Isolation, Identification, Applications. Springer New York, New York, NY, pp. 3631-3675.

Röttig, A., Steinbüchel, A., 2013. Acyltransferases in bacteria. Microbiol. Mol. Biol. Rev. 77, 277-321.

Sandoval-Denis, M., Guarro, J., Cano-Lira, J.F., Sutton, D.A., Wiederhold, N.P., de Hoog, G.S., Abbott, S.P., Decock, C., Sigler, L., Gené, J., 2016. Phylogeny and taxonomic revision of Microascaceae with emphasis on synnematous fungi. Stud. Mycol. 83, 193-233.

Schellenberger, S., Drake, H.L., Kolb, S., 2011. Functionally redundant cellobiose-degrading soil bacteria respond differentially to oxygen. Appl. Environ. Microbiol. 77, 6043-6048.

Shachak, M., 2011. Ecological textures: ecological systems in the northern Negev as a model. Ecol. Environ. Conserv. 2, 18-29.

Shelp, B.J., Bown, A.W., Zarei, A., 2017. 4-Aminobutyrate (GABA): a metabolite and signal with practical significance. Botany 95, 1015-1032.

Sher, Y., Zaady, E., Ronen, Z., Nejidat, A., 2012. Nitrification activity and levels of inorganic nitrogen in soils of a semi-arid ecosystem following a drought-induced shrub death. Eur. J. Soil Biol. 53, 86-93.

Shukla, P.R., Skeg, J., Buendia, E.C., Masson-Delmotte, V., Pörtner, H.-O., Roberts, D.C., Zhai, P., Slade, R., Connors, S., van Diemen, S., Ferrat, E., Haughey, S., Luz, S., Neogi, M., Pathak, J., Petzold, J., Portugal Pereira, P., Vyas, E., Huntley, K., Kissick, M., Belkacemi, J.M., 2019. Climate Change and Land: an IPCC special report on climate change, desertification, land degradation, sustainable land management, food security, and greenhouse gas fluxes in terrestrial ecosystems. Intergovernmental Panel on Climate Change.

Singer, A., 2007. The soils of Israel. Springer, Berlin.

Smith, M.D., 2011. An ecological perspective on extreme climatic events: a synthetic definition and framework to guide future research. J. Ecol. 99, 656-663.

Srivastava, M.P., Tandon, R.N., Bhargava, S.N., Ghosh, A.K., 1966. Studies on fungal diseases of some tropical fruits IV. Some new fungi. Mycopathol. Mycol. Appl. 30, 203-208.

Stavi, I., Shem-Tov, R., Chocron, M., Yizhaq, H., 2015. Geodiversity, self-organization, and health of three-phase semi-arid rangeland ecosystems, in the Israeli Negev. Geomorphology 234, 11-18.

Stavi, I., Rachmilevitch, S., Hjazin, A., Yizhaq, H., 2018a. Geodiversity decreases shrub mortality and increases ecosystem tolerance to droughts and climate change. Earth Surf. Processes Landforms 43, 2808-2817.

Stavi, I., Rachmilevitch, S., Yizhaq, H., 2018b. Small-scale geodiversity regulates functioning, connectivity, and productivity of shrubby, semi-arid rangelands. Land Degrad. Dev. 29, 205-209.

Stavi, I., Rachmilevitch, S., Yizhaq, H., 2019. Geodiversity effects on soil quality and geo-ecosystem functioning in drylands. Catena 176, 372-380.

Stein, A., Gerstner, K., Kreft, H., 2014. Environmental heterogeneity as a universal driver of species richness across taxa, biomes and spatial scales. Ecol. Lett. 17, 866-880.

Stojanowic, A., Mander, G.J., Duin, E.C., Hedderich, R., 2003. Physiological role of the F420-non-reducing hydrogenase (Mvh) from Methanothermobacter marburgensis. Arch. Microbiol. 180, 194-203.

Sze, M., Doonan, J., Mcdonald, J.E., Harris, R.N., Dewar, M., 2020. Factors that shape the host microbiome, in: Antwis, R.E., Harrison, X.A., Cox, M.J. (Eds.), Microbiomes of Soils, Plants and Animals. Cambridge University Press, Cambridge, pp. 55-57.

Tedersoo, L., Bahram, M., Põlme, S., Kõljalg, U., Yorou, N.S., Wijesundera, R., Ruiz, L.V., Vasco-Palacios, A.M., Thu, P.Q., Suija, A., Smith, M.E., Sharp, C., Saluveer, E., Saitta, A., Rosas, M., Riit, T., Ratkowsky, D., Pritsch, K., 
Põldmaa, K., Piepenbring, M., Phosri, C., Peterson, M., Parts, K., Pärtel, K., Otsing, E., Nouhra, E., Njouonkou, A.L., Henrik Nilsson, R., Morgado, L.N., Mayor, J., May, T.W., Majuakim, L., Jean Lodge, D., Lee, S.S., Larsson, K.-H., Kohout, P., Hosaka, K., Hiiesalu, I., Henkel, T.W., Harend, H., Guo, L.-D., Greslebin, A., Grelet, G., Geml, J., Gates, G., Dunstan, W., Dunk, C., Drenkhan, R., Dearnaley, J., De Kesel, A., Dang, T., Chen, X., Buegger, F., Brearley, F.Q., Bonito, G., Anslan, S., Abell, S., Abarenkov, K., 2014. Global diversity and geography of soil fungi. Science

346.

https://doi.org/10.1126/science.1256688

Teixeira, M.M., Moreno, L.F., Stielow, B.J., Muszewska, A., Hainaut, M., Gonzaga, L., Abouelleil, A., Patané, J.S.L., Priest, M., Souza, R., Young, S., Ferreira, K.S., Zeng, Q., da Cunha, M.M.L., Gladki, A., Barker, B., Vicente, V.A., de Souza, E.M., Almeida, S., Henrissat, B., Vasconcelos, A.T.R., Deng, S., Voglmayr, H., Moussa, T.A.A., Gorbushina, A., Felipe, M.S.S., Cuomo, C.A., de Hoog, G.S., 2017. Exploring the genomic diversity of black yeasts and relatives (Chaetothyriales, Ascomycota). Stud. Mycol. 86, 1-28.

Toju, H., Tanabe, A.S., Yamamoto, S., Sato, H., 2012. High-coverage ITS primers for the DNA-based identification of ascomycetes and basidiomycetes in environmental samples. PLoS One 7, e40863.

Toju, H., Kurokawa, H., Kenta, T., 2019. Factors influencing leaf- and root-associated communities of bacteria and fungi across 33 plant orders in a grassland. Front. Microbiol. 10, 241.

Upton, R.N., Bach, E.M., Hofmockel, K.S., 2019. Spatio-temporal microbial community dynamics within soil aggregates. Soil Biol. Biochem. 132, 58-68.

Wen, X., Yang, S., Horn, F., Winkel, M., Wagner, D., Liebner, S., 2017. Global biogeographic analysis of methanogenic archaea identifies community-shaping environmental factors of natural environments. Front. Microbiol. 8, 1339.

Wüst, P.K., Foesel, B.U., Geppert, A., Huber, K.J.,
Luckner, M., Wanner, G., Overmann, J., 2016. Brevitalea aridisoli, B. deliciosa and Arenimicrobium luteum, three novel species of Acidobacteria subdivision 4 (class Blastocatellia) isolated from savanna soil and description of the novel family Pyrinomonadaceae. Int. J. Syst. Evol. Microbiol. 66, 3355-3366.

$\mathrm{Xu}$, J., Mahmud, T., Floss, H.G., 2003. Isolation and characterization of 27-0-demethylrifamycin SV methyltransferase provides new insights into the post-PKS modification steps during the biosynthesis of the antitubercular drug rifamycin B by Amycolatopsis mediterranei S699. Arch. Biochem. Biophys. 411, 277-288.

Yergaliyev, T.M., Alexander-Shani, R., Dimerets, H., Pivonia, S., Bird, D.M., Rachmilevitch, S., Szitenberg, A., 2020. Bacterial community structure dynamics in Meloidogyne incognita-infected roots and its role in worm-microbiome interactions. mSphere 5. https://doi.org/10.1128/mSphere.00306-2 0

Yizhaq, H., Stavi, I., Shachak, M., Bel, G., 2017. Geodiversity increases ecosystem durability to prolonged droughts. Ecol. Complex. 31, 96-103.

Yu, H.-F., Huang, F.-L., Lin, C.-J., 2011. Dual coordinate descent methods for logistic regression and maximum entropy models. Mach. Learn. 85, 41-75.

Zedda, L., Rambold, G., 2015. The diversity of lichenised fungi: ecosystem functions and ecosystem services, in: Upreti, D.K., Divakar, P.K., Shukla, V., Bajpai, R. (Eds.), Recent Advances in Lichenology: Modern Methods and Approaches in Lichen Systematics and Culture Techniques. Springer India, New Delhi, pp. 121-145.

Zhang, B., Wu, X., Tai, X., Sun, L., Wu, M., Zhang, W., Chen, X., Zhang, G., Chen, T., Liu, G., Dyson, P., 2019. Variation in actinobacterial community composition and potential function in different soil ecosystems belonging to the arid Heihe River Basin of 
bioRxiv preprint doi: https://doi.org/10.1101/2021.03.08.434393; this version posted March 16, 2021. The copyright holder for this preprint (which was not certified by peer review) is the author/funder, who has granted bioRxiv a license to display the preprint in perpetuity. It is made available under aCC-BY 4.0 International license.

Northwest China. Front. Microbiol. 10, 2209 